\title{
Voltage support in hybrid AC-DC grid by wind power plants and VSC
}

\section{Döring, Dominik Ivo; Dhua, Debasish; Huang, Shaojun; Wu, Qiuwei}

\section{Published in:}

International Journal of Electrical and Electronic Engineering and Telecommunications

Link to article, DOI:

10.18178/ijeetc.7.4.165-171

Publication date:

2018

Document Version

Publisher's PDF, also known as Version of record

Link back to DTU Orbit

\section{Citation $(A P A)$ :}

Döring, D. I., Dhua, D., Huang, S., \& Wu, Q. (2018). Voltage support in hybrid AC-DC grid by wind power plants and VSC. International Journal of Electrical and Electronic Engineering and Telecommunications, 7(4), 165-171. https://doi.org/10.18178/ijeetc.7.4.165-171

\section{General rights}

Copyright and moral rights for the publications made accessible in the public portal are retained by the authors and/or other copyright owners and it is a condition of accessing publications that users recognise and abide by the legal requirements associated with these rights.

- Users may download and print one copy of any publication from the public portal for the purpose of private study or research.

- You may not further distribute the material or use it for any profit-making activity or commercial gain

- You may freely distribute the URL identifying the publication in the public portal 


\title{
Voltage Support in Hybrid AC-DC Grid by Wind Power Plants and VSC
}

\author{
Dominik Ivo Döring, Debasish Dhua, Shaojun Huang, and Qiuwei Wu \\ Centre for Electric Power and Energy, Department of Electrical Engineering, Technical University of Denmark (DTU), \\ Elektrovej 325, 2800 Kgs. Lyngby, Denmark \\ Email: \{dominik.doering19, debasish.dhua\}@gmail.com; \{shuang, qw\} @elektro.dtu.dk
}

\begin{abstract}
Previously, the large conventional fossil fuel plants were in charge of supporting the grid voltage by supplying the reactive power. They will be gradually replaced with renewable energy sources (RES), leading to a more volatile power system with low inertia. This paper investigates the performance of voltage source converters (VSC) in establishment of voltages in a future power system featured with hybrid AC-DC grids and wind power plants. An optimal power flow (OPF) model for multiple planning periods is developed to optimally dispatch the reactive power of different available reactive power sources, including wind power plants, HVDC converters and traditional generators. The developed OPF model is ready to work at the top level of a hierarchical voltage control scheme. Case studies demonstrated that the developed model was able to reduce active power losses and improve the voltage profiles in the overall system.
\end{abstract}

Index Terms-Hybrid AC-DC, optimal power flow (OPF), $H V D C$, voltage control

\section{INTRODUCTION}

The most important renewable energy source (RES) together with hydro and solar power is wind energy. The number of wind power plants (WPPs) has increased significantly in last decade and will continue in coming years [1]. With the growing WPPs and the gradual replacement of large conventional alternators, the desired ancillary performances set by the grid code operators on WPPs has also been enhanced, e.g. fault ride-through capability, reactive power supply and frequency-active power control [2]. WPPs are usually placed far away from the load centers due to their space requirements and requirement for good wind conditions. Therefore, WPPs are developed with long distance electrical transmission infrastructure. High voltage DC (HVDC) transmission is an effective solution to this expensive long-distance bulk power transmission. Including the reduced transmission material requirements, HVDC transmission is also advantageous over high voltage AC (HVAC) transmission due to the absence of reactive power transmission in it and subsequent joule losses. However, the converter substations at the HVDC terminals require additional installation and maintenance cost. With the

Manuscript received January 5, 2018; revised July 18, 2018. increment of WPPs, the hybrid grid is receiving relevance and popularity.

The voltage level at different buses in a grid must be kept within acceptable limit $\pm 10 \%$ for steady operating conditions [3]. The voltage level in a grid is a function of reactive power flow at different operating nodes [4]. In a hybrid grid, the voltage source converters (VSCs) at the HVDC terminals can play the key role in maintaining the voltage level within desired limit. The problem of Voltage Control (VC) can be solved locally in multiagent system by coordinating the reactive power reserves economically [5]. Reactive power management is suggested hierarchically by subdividing it into three levels from local bus over sub-areas with a strong electrical coupling to the whole national power grid [6], [7]. An optimal power flow study is a more justified approach to solve the VC problem, where the voltage and reactive power profile are estimated periodically for every bus in high RES penetration environment [8], [9]. However, to fulfil the requirements of the future grid, the optimal power flow (OPF) method must include the characteristics of a hybrid network in it. The performance of the hybrid network with conventional generators and the power flow involved in it, are previously developed in [10]-[12]. The aim of this work is to develop a tool in order to optimally control the voltage in a hybrid AC-DC system with WPPs as an additional reactive power source. Thereafter, the most suitable voltage set-points and reactive power outputs are recommended for the conventional generators, WPPs and the VSCs at HVDC terminals. The objective of the OPF study is to minimize the transmission losses in the hybrid network. The entire paper can be outlined as follows. Section II depicts the reactive voltage control with hierarchical model. Section III develops the hybrid network used in this study and the impact of different power flow algorithms on it. Section IV describes the results and discusses the relevance of the proposed technique. Section V concludes the work with future extension possibilities.

\section{Voltage CONTROL With HiERARChICAL MODEL}

The traditional VC method is updated with the hierarchical reactive power flow control method to cope up with the rate of generation fluctuations of RES [13], [14]. 


\section{A. Structure of Hierarchical Model}

Besides, the possibilities of integrating the WPPs and HVDC lines into the power system VC strategies, there are multiple advantages of implementing the hierarchical model (Fig. 1) [13], e.g. 1) reduced fluctuations of the predefined voltage profile, 2) enhanced 'var' reserves for emergency conditions, 3) close to unity power factor transmission, 4) reduced transmission loss, 5) better utilization of 'var' sources.

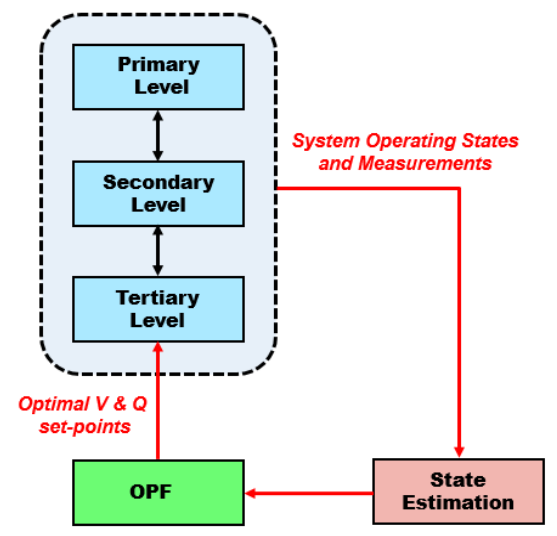

Figure 1. Hierarchical voltage control method.

The hierarchical VC method is organized in three levels of system voltage regulation; primary, secondary and tertiary in the inner loop. The outer loop consists of State Estimation which is forwarded to OPF, which determines the optimum set-points. The set-points are transmitted to the highest level of VC. The three levels overlap with one another and form a closed-loop control mechanism. They are distinguished by their speed of dynamics with the primary level is the fastest one and so on. Moreover, they are also separated spatially where the primary level takes care of the local bus voltage and the complete system is governed by the tertiary level [6]. The OPF method uses the conventional power flow methods to optimize a defined problem. This can be the minimization of generation cost or the maximization of security margins. However, in several cases the minimization of the system transmission losses is of prime interest. The optimization can be implemented to find the best reference values for the voltage profile of a system. The OPF method constantly updates the voltage (V) and reactive power (Q) set-points based on the system operating conditions and latest measurements of bus voltages, angles and active-reactive injections. OPF also offers the possibility to add the system constraints e.g. line flow, generator limits etc. while optimizing for the best solution.

\section{B. OPF for the System Voltage Control}

To develop the OPF model for VC, the equalities and inequalities involving the active-reactive power injections for each bus need to be identified. The active-reactive power flow can be expressed as follows,

$$
\begin{gathered}
P_{i n j}=P_{G}-P_{D} \\
Q_{i n j}=Q_{G}-Q_{D}
\end{gathered}
$$

where $P_{i n j}$ and $Q_{i n j}$ are the active-reactive power injections at any bus with $P_{G}, Q_{G}$ and $P_{D}, Q_{D}$ are generation and demand at the specified bus. For $i$ th bus, the generation and demand can be expressed in terms of bus voltage and admittance parameters as expressed as

$$
\begin{gathered}
P_{i n j, i}=\left|V_{i}\right| \sum_{j=1}^{n}\left|V_{j}\right|\left(G_{i j} \cos \delta_{i j}+B_{i j} \sin \delta_{i j}\right) \\
Q_{i n j, i}=\left|V_{i}\right| \sum_{j=1}^{n}\left|V_{j}\right|\left(G_{i j} \sin \delta_{i j}-B_{i j} \cos \delta_{i j}\right)
\end{gathered}
$$

where $G_{i j}$ and $B_{i j}$ represent the conductance and susceptance of the line connecting $i$ th and $j$ th buses. An optimal power flow is an optimization method applied on the power flow on the interconnected system. The equalities and inequalities apply limit to the system quantities and optimize the power flow to fulfil a specified objective function [15]. In this study, the transmission loss in the system is defined as the objective function while maintain the $\mathrm{VC}$.

\section{SYSTEM OVERVIEW AND OPTIMIZATION}

\section{A. AC Grid Modelling}

An 8-bus AC-transmission system is developed as depicted in Fig. 2. The distribution systems are represented by lumped loads. They are connected together with the generators to 4 medium-voltage (MV) buses. The transmission lines are represented as $\pi$-model and the transformer as series equivalent reactance. Line impedance, shunt susceptance and transformer reactance can be found in Fig. 2.

TABLE I: GENERATION AND LOAD DATA FOR PURE-AC GRID SIMULATION (PIN MW AND Q IN MVAR)

\begin{tabular}{lllllll}
\hline Type & $P_{G}$ & $P_{G, \min }$ & $P_{G, \max }$ & $Q_{G}$ & $Q_{G, \min }$ & $Q_{G, \max }$ \\
\hline G1 & - & 0 & 1530 & - & -720 & 1440 \\
G2 & 100 & - & - & - & -240 & 480 \\
WPP1 & 150 & - & - & - & -100 & 100 \\
WPP2 & 150 & - & - & - & -150 & 150 \\
WPP3 & 225 & - & - & - & -150 & 150 \\
L1 & -285 & - & - & -93.67 & - & - \\
L2 & -380 & - & - & -124.9 & - & - \\
L3 & -285 & - & - & -93.67 & - & - \\
\hline
\end{tabular}

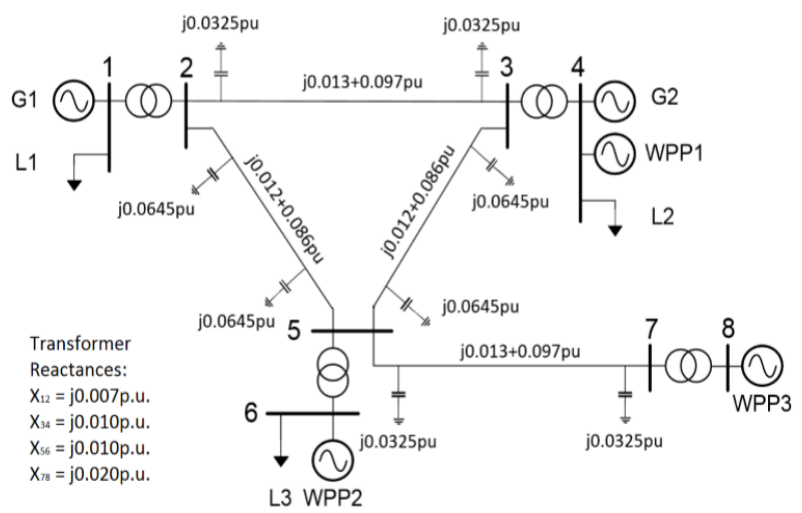

Figure 2. Sketch of the pure AC grid.

The network consists of 2 conventional generators (G1, G2) supplying with active-reactive power to the system 
where, G1 is the reference machine at the slack bus 1 . There are three WPPs, each representing large onshore or offshore wind farms. The wind turbine generators (WTGs) are lumped together and modelled as a generator. Their reactive power capability depends on the scenario, described in the next section. The grid has 3 load centres, located at bus 1 , bus 4 , and bus 6 .

The optimization algorithm consists of three parts; the grid data and the solver in the main program, the objective function and a function containing the equality and inequality constraints as elaborated in [16]. For the inequality constraints, the active-reactive power generator limits are implemented as in Table I. Depending on the three different case studies, the 'var' limits for the WPP are set as in Table I; 'var' is set as zero in case of no reactive power support.

Furthermore, the apparent power flows in each line are calculated, using the state variables and the admittance matrix following the common power flow equations explained in [15]. The apparent power flow limits for the transformers and transmission lines are listed in Table II.

TABLE II: APPARENT POWER FLOW LIMIT

\begin{tabular}{ccc}
\hline From Bus & To Bus & $S_{\max }($ MVA $)$ \\
\hline 1 & 2 & 1800 \\
2 & 3 & 448 \\
2 & 5 & 498 \\
3 & 4 & 1200 \\
3 & 5 & 498 \\
5 & 6 & 448 \\
5 & 7 & 1200 \\
7 & 8 & 600 \\
\hline
\end{tabular}

\section{B. HVDC Extension}

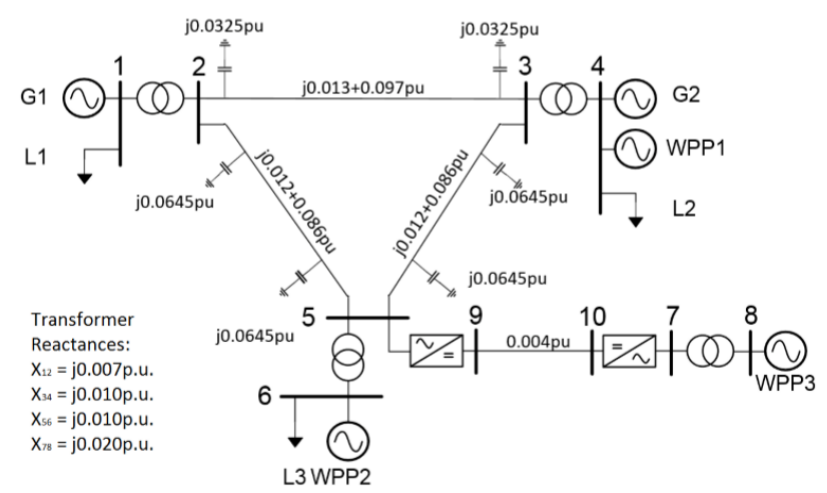

Figure 3. Sketch of hybrid AC-DC grid.

In this step, the pure AC system is extended to a hybrid network by including the HVDC interconnection with its terminal VSCs as indicated in Fig. 3. In this case, the AC line between bus 5 and 7 is replaced by the direct current line, the converters and two DC buses. To implement the HVDC line, the DC conductance matrix $G_{D C}$ is included with $\mathrm{AC}$ conductance matrix $G_{A C}$ in the grid data section; the terminal DC bus voltages (for Bus 9 and 10) $E_{9}$ and $E_{10}$ are included with pure AC-grid state variable vectors with suitably implementing the AC-DC conversion equations though VSCs as elaborated in [17], [18].
TABLE III: GENERATION AND LOAD DATA FOR HYBRID AC-DC GRID SIMULATION (PIN MW AND QIN MVAR)

\begin{tabular}{lllllll}
\hline Type & $P_{G}$ & $P_{G, \min }$ & $P_{G, \max }$ & $Q_{G}$ & $Q_{G, \min }$ & $Q_{G, \max }$ \\
\hline G1 & - & 0 & 1530 & - & -720 & 1440 \\
G2 & 100 & - & - & - & -240 & 480 \\
WPP1 & 300 & - & - & - & -100 & 100 \\
WPP2 & 300 & - & - & - & -150 & 150 \\
WPP3 & 450 & - & - & - & -150 & 150 \\
L1 & -475 & - & - & -156.1 & - & - \\
L2 & -475 & - & - & -156.1 & - & - \\
L3 & -380 & - & - & -124.9 & - & - \\
\hline
\end{tabular}

The only changes made in the objective function is the higher wind power production together with the new load data as indicated in Table III. The active-reactive power injections by the VSCs can be modelled by modifying the equality constraints as indicated in (5).

$$
P_{V S C}=\left[\begin{array}{c}
0 \\
0 \\
0 \\
0 \\
P_{D C, i n j, 9->5} \\
0 \\
P_{D C, i n j, 10->7} \\
0
\end{array}\right] ; \quad Q_{V S C}=\left[\begin{array}{c}
0 \\
0 \\
0 \\
0 \\
Q_{D C, i n j, 9->Q} \\
0 \\
Q_{D C, i n j, 10->7} \\
0
\end{array}\right]
$$

In this case, the converter loss is also included in the equality constraints which is shown in (6), where, $I_{V S C_{i}}$ is the current through $i$ th VSC; the converter dependent values $a, b, c$ are taken from [17].

$$
P_{\text {loss }, V S C_{i}}=a+b I_{V S C_{i}}+c I_{V S C_{i}}^{2}
$$

Therefore, the final equality constraints in presence HVDC line can be represented as in (7-8).

$$
\begin{gathered}
0=P_{G}-P_{D}+P_{D C, i n j}+P_{l o s s, V S C} \\
0=Q_{G}-Q_{D}+Q_{D C, i n j}
\end{gathered}
$$

\section{RESULTS AND DISCUSSION}

The case studies are developed in three steps: 1) pure AC grid, 2) extended grid with a HVDC line, connecting a WPP to the main AC grid, 3) the tool is modified to optimize not only one time step, but also with whole time series (24 hours).

\section{A. AC Grid Simulation}

For the AC grid, three subcases are studied as follows, the conventional power flow is conducted using the Modified Newton-Raphson (MNR) method. Thereafter, the optimal power flow is applied on the same grid. In both the cases two conventional generators only supply reactive power. In a next step, the WPPs are used as additional 'var' sources to improve the system performance and to reduce the overall losses. For the reference base case, the voltages at the slack and PV 
buses are fixed at a set-point of $V=1$ p.u. To find the optimum values, the voltage at bus 4 is released in the OPF.

In case of conventional power flow, the voltages at bus 1 and bus 4 are as expected at $V=1$ p.u. (Fig. 4 (a)), the remaining voltages of the grid follow the controlled buses and their magnitudes depend on the passive influence of the grid as well as the generation and load. In Fig. 4 (a) the voltages at bus 2 and bus 3 are seen to be close to the reference of the controlled nodes since they are electrically strong coupled. However, bus 5 to bus 8 are far away from reactive power support which let their voltages decrease significantly, close to the lower limit of $V=0.91$ p.u. This is due to the reactive power consumption at the load bus 6 and the 'var' demand of the lines and transformers. Whereas, the OPF determined a significant higher set-point for the PV bus 4 (in Fig. 4 (b)). This provokes all uncontrolled buses to increase their voltage level considerably. The origin of this boost is an optimized reactive power dispatch; since the slack bus voltage level is fixed, the PV bus (bus 4) clearly injects higher reactive power. This changes in the 'var' dispatch, followed by an optimized voltage profile, influence the active power losses of the system.

The OPF grid situation causes higher losses in the two lines, which connect the PV bus with the rest of the system. However, the losses in the other lines are reduced (10.6 MW to 10.2 MW). This leads to a total reduction in Joule losses of ca. $\Delta P=0.4 \mathrm{MW}$ which corresponds to $3.86 \%$ of the reference losses.

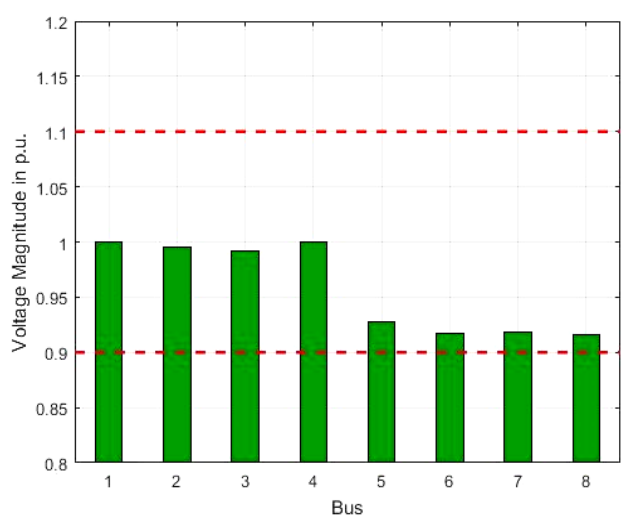

(a)

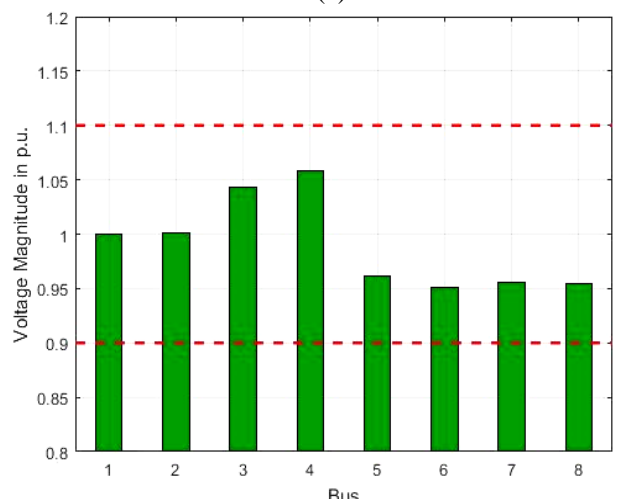

(b)

Figure 4. Voltage profiles in a) MNR method and b) OPF method with no WPPs 'var' support.

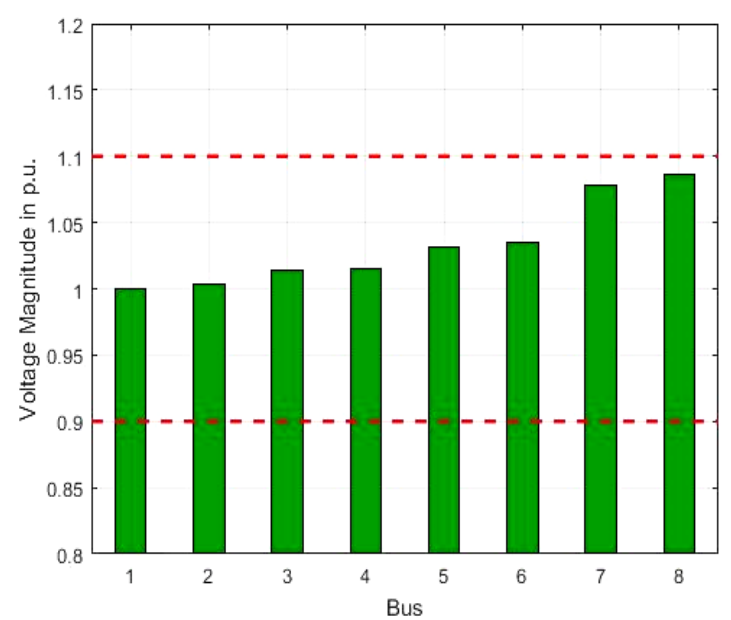

Figure 5. Voltage profile for OPF method in pure-AC grid with WPPs 'var' support.

In the third case, the WPPs are also contributing 'var'. WPP1 contribute to the VC capability of the conventional generator. However, now it possible to actively influence the voltage level at bus 6 and bus 8 by injecting or absorbing vars. This results in the voltages magnitudes significant higher at bus 5 to bus 8 (in Fig. 5) compared to the case without 'var' support from the WPPs.

In this subcase, the reactive power generations, which where before only injected at bus 1 and bus 4 , are now distributed to all nodes with connected WPPs. This has two advantages, firstly the transfer capacity of the lines is increased for active power; secondly the heating losses are significantly lower due to the lower reactive currents. This leads to a total loss reduction (10.6 MW to 7.08 MW) of ca. $\Delta P=3.54 \mathrm{MW}$ which corresponds to $33.33 \%$ of the base case losses.

\section{B. Hybrid Grid Simulation}

To analyse the behaviour of the hybrid AC-DC network, an HVDC line is implemented to connect the WPP3 at bus 8 through the step-up transformer to the main AC grid at bus 5. Along with the WPPs, the terminal VSCs also play key role in the system dynamics. This case involves four subcases as follows; initially, G1 and G2 only supply 'var' to the grid where the HVDC line decouples the AC grid into two; in the 2nd subcase, VSCs contribute 'var' to the system; in the 3rd subcase only WPPs take care of the VC; finally, both WPPs and VSCs support the grid VC.

In the first subcase (Fig. 6 (a)), the voltage of bus 4 is seen to almost touching the maximum limit of $v=1.1 \mathrm{p}$.u. to provide necessary 'var' support since there is no other active 'var' support in the system and the slack bus voltage is constant at $v=1.0$ p.u. Moreover, there is no reactive power source existing in the southern part of the network, voltages at bus 5 and bus 6 are very low to import the 'var' from the northern part of the network. In the next two subcases (Fig. 6 (b) and (c)) the voltage profiles at bus 5 and bus 6 are seen to be improved from the former subcase (shown in Fig. 6 (a)) due to the 'var' support from VSC and WPP2 in respective subcases. 


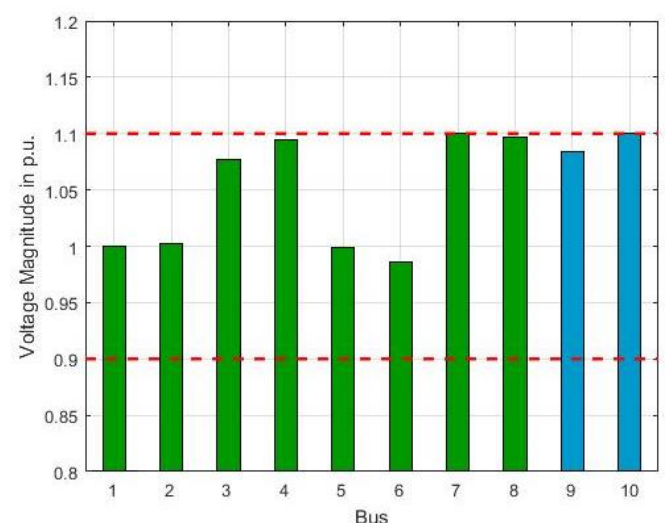

(a)

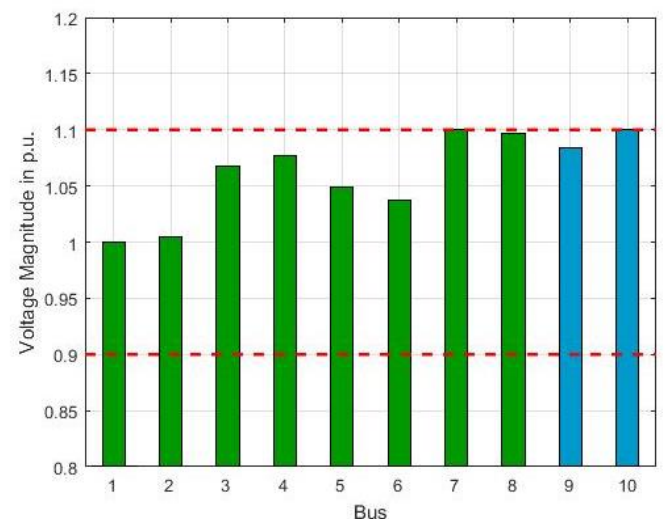

(b)

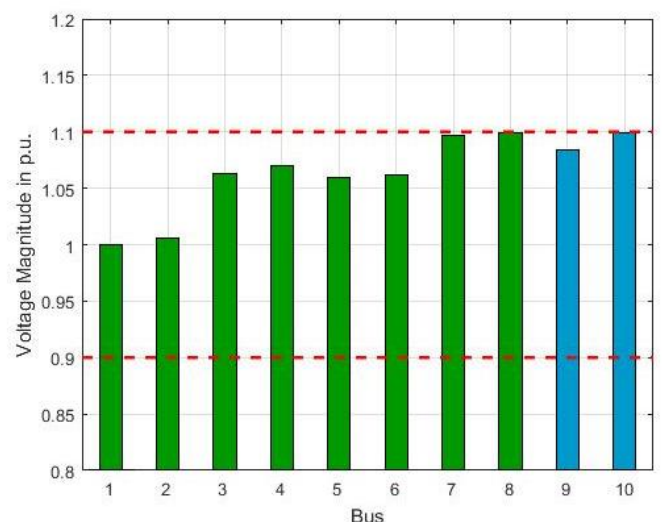

(c)

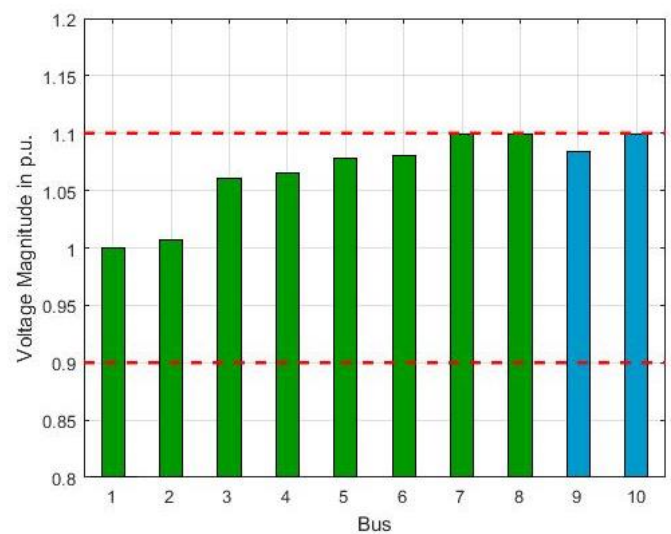

(d)

Figure 6. Voltage profile for a) No 'var' support, b) Only VSC 'var' support, c) Only WPP 'var' support and d) VSC \& WPP 'var' support.
Moreover, bus 4 voltage is no more touching the maximum limit of $v=1.1$ p.u. as indicated in Fig 7 (b) and (c), because the 'var' requirement in the southern part of the network is locally compensated by VSC and WPP2. In the last subcase (Fig. 6 (d)), with the support of VSCs and WPPs the best result with high voltage levels for a low-loss is optimized. In this subcase no long distance 'var' transmission is required. It can be supplied locally by the VSCs and WPPs. The voltage at bus 7 or bus 8 is slightly higher or nearly balanced in the last subcase depending on the VSC that is injecting the reactive power The voltage in the DC link is controlled by the VSC at the WPP3 and kept at the maximum for bus 10. The lower voltage at bus 9 is seen due to the voltage drop over the line resistance, depending on the amount of transferred power from WPP3 into the network. The voltages at bus 9 and bus 10 are seen to be identical in all four subcases (indicated in Fig. 6) because they are kept at their maximum limit and unable to contribute 'var' to the AC network by being decoupled by the HVDC line.

The objective function defined while maintaining the voltage profile by providing 'var' support, is minimizing the transmission loss in the whole hybrid AC-DC network. The total active power loss in four subcases are listed in Table IV.

TABle IV: ACtive Power Losses in Four DifFERENT SubCASES

\begin{tabular}{ll}
\hline $\begin{array}{c}\text { Subcases (Hybrid AC-DC grid } \\
\text { modelling) }\end{array}$ & $\begin{array}{c}\text { Active power loss } \\
\text { (MW) }\end{array}$ \\
\hline No 'var' support & 44.15 \\
VSC 'var' support & 42.06 \\
WPP 'var' support & 40.62 \\
VSC \& WPP 'var' support & 40.31 \\
\hline
\end{tabular}

Based on the active power losses listed in Table IV, it is clear that the local distributed 'var' injections that lead to better voltage profile, causing reduced system losses.

\section{Time Series Simulation}

For the time series simulations, only the two extreme subcases are considered; no 'var' support from WPPs and VSC at bus 5 and full support. The wind power output shown in Fig. 7 is calculated according to the real wind speed measurement for a day in April in Germany [19].

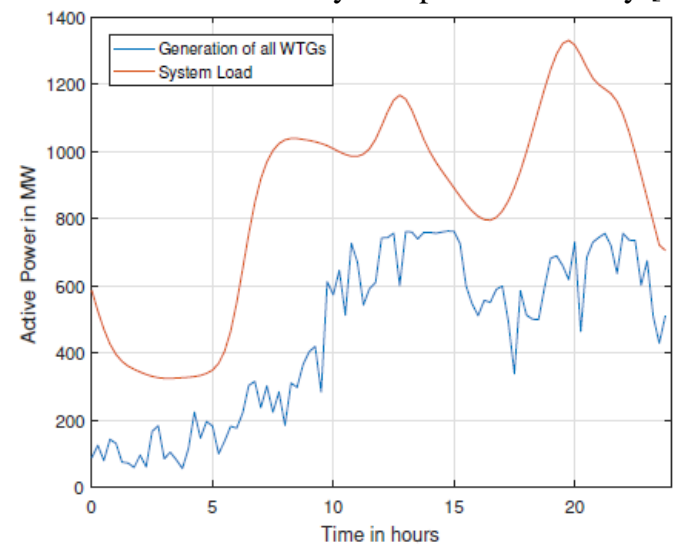

Figure 7. Load demand and wind power production over the period of $24 \mathrm{hrs}$. 


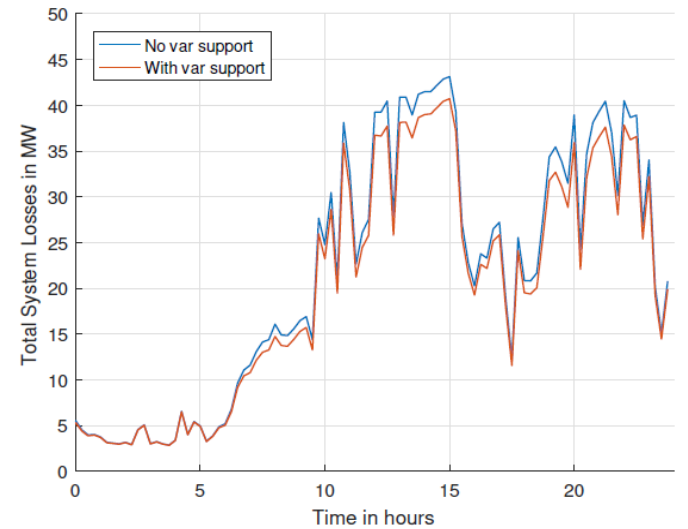

Figure 8. Total active power losses in two subcases for time series simulation.

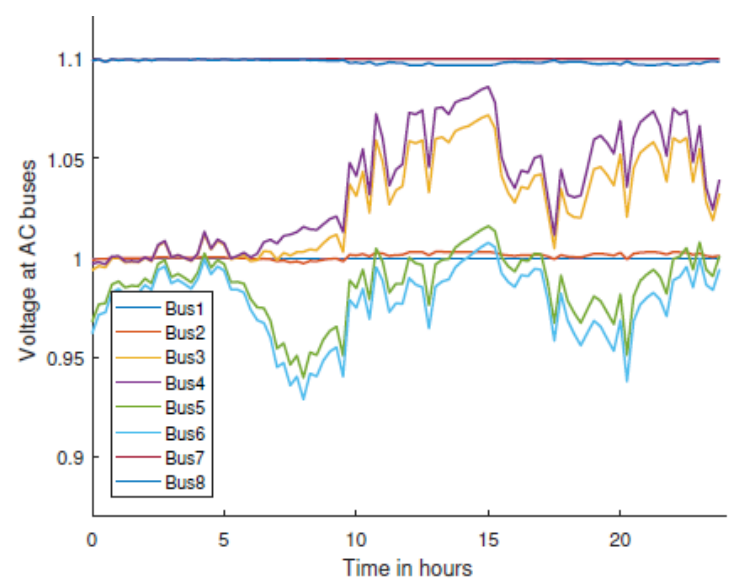

(a)

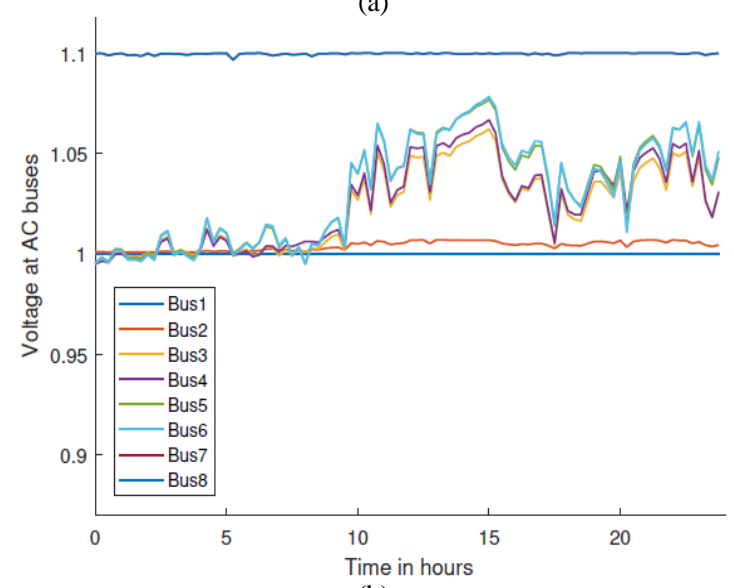

(b)

Figure 9. AC-bus voltage a) without and b) with 'var' support from WPP \& VSC in hybrid network

Fig. 8 compares the active power losses of the hybrid system for the two extreme subcases. It can be seen that with local and distributed 'var' support the overall system loss can be optimized.

From the results shown in Fig. 9, it is seen that with full support from VSC and WPPs the voltages at bus 3 and bus 4 are now lower since less reactive power needs to be transmitted to the southern part of the network. Whereas, the voltage magnitudes at bus 5 and bus 6 are even higher and can kept at an optimum level with low losses. Therefore, the time series simulation result leads to identical conclusion as hybrid grid simulation results.

\section{CONCLUSION AND FUTURE WORK}

This paper illustrates how the OPF method supports the voltage at different buses of a hybrid AC-DC network with high penetration of wind energy. In this process, the WPPs and VSCs play a key role in distribution of 'var' in the network and reduce the long-distance transmission of reactive power from conventional generators. To test the developed OPF tool under changing system conditions, a time-series analysis has been conducted under varying wind power production and load demand. It shows that the active power losses over this time period can be significantly reduced by WPPs and VSCs while improving the system voltage conditions. The developed tool can be implemented in future for larger hybrid network with redefined objective function, e.g., generation cost minimization, 'var' production minimization, transmission and distribution optimizations.

\section{ACKNOWLEDGMENT}

The work was supported by the "Voltage control on the transmission grid using wind power at other voltage levels (VOLATILE)' project (EU 'ERA-Net Smart Grids Plus').

\section{REFERENCES}

[1] Energienet.dk. Electricity Security of Supply Report 2016. Technical report. Fredericia, 2016.

[2] I. D. Margaris, A. D. Hansen, P. Sørensen, and N. D. Hatziargyriou, "Illustration of modern wind turbine ancillary services," Energies, vol. 3, no. 6, pp. 1290-1302, 2010.

[3] H. Berndt, et al., Transmission Code 2007. Network and System Rules of the German Transmission System Operators, Technical Report. Verband der Netzbetreiber VDN e.V. beim VDEW, 2007.

[4] P. Kundur, Power System Stability and Control, New York: McGraw-Hill, Inc., 1994.

[5] D. T. Duong L. Kalemba, K. Uhlen, and S. Løvlund, “A scheme for coordinated secondary voltage control for systems with multiple VAr reserves," in Proc. IEEE Power and Energy Society Innovative Smart Grid Technologies Conf., 2015.

[6] S. C. M. Pozzi, C. Sabelli, and A. Serrani, "The coordinated automatic voltage control of the Italian transmission grid--Part I: Reasons of the choice and overview of the consolidated hierarchical system," IEEE Trans. on Power Systems, vol. 19, no. 4, pp. 1723-1732, 2004.

[7] S. Corsi, F. De Villiers, and R. Vajeth, "Secondary voltage regulation applied to the South Africa transmission grid," in Proc. of IEEE PES General Meeting, 2010, pp. 1-8.

[8] B. Hu, C. A. Cañizares, and M Liu, "Secondary and Tertiary Voltage Regulation based on optimal power flows," in Proc. IREP Symposium Bulk Power System Dynamics and Control, Rio de Janeiro, 2010, pp. 1-6.

[9] Q. Guo, H. Sun, Bin Wang, B. Zhang, W. Wu, and L. Tang, "Hierarchical automatic voltage control for integration of largescale wind power: Design and implementation," Electric Power Systems Research, vol. 120, pp. 234-241, 2015.

[10] A. Panosyan and B. R. Oswald, "Modified Newton-Raphson Load Flow Analysis for Integrated AC/DC Power Systems," in Proc. 39th Int. Universities Power Engineering Conf., 2005, pp. 12231227.

[11] J. Beerten, S. Cole, and R. Belmans, "Generalized steady-state VSC MTDC model for sequential AC/DC power flow algorithms," IEEE Trans. on Power Systems, vol. 27, no. 2 pp. 821-829, 2012.

[12] A. Pizano-Martinez, C. R. Fuerte-Esquivel, H. Ambriz-Pérez, and E. Acha, "Modeling of VSC-based HVDC systems for a newtonraphson OPF algorithm," IEEE Trans. on Power Systems, vol. 22, no. 4, pp. 1794-1803, 2007. 
[13] S. Corsi, Voltage Control and Protection in Electrical Power Systems, London: Springer-Verlag, 2015.

[14] M. Larsson, "Coordinated voltage control in electric power systems," Ph.D. thesis, Lund University, 2000, pp. 1-203.

[15] A. J. Wood, B. F. Wollenberg, and G. B. Sheblé, Power Generation, Operation, and Control, 2014, 3rd edition, ch. 8.

[16] MathWorks. Constrained Nonlinear Optimization Algorithms MATLAB Documentation, [Online]. Available: https://se.mathworks.com/help/optim/ug/constrained-nonlinearoptimization-algorithms.html\#brnpd5f

[17] M. Aragüés-Peñalba, A. E. Alvarez, S. G. Arellano, and O. Gomis-Bellmunt, "Optimal power flow tool for mixed highvoltage alternating current and high-voltage direct current systems for grid integration of large wind power plants," IET Renewable Power Generation, vol. 9, no. 8, p. 876, 2015.

[18] D. Dhua, S. Huang, and Q. Wu, "Optimal power flow modelling and analysis of hybrid AC-DC grids with offshore wind power plant," presented at the 4rd Int. Conf. on Power and Energy Systems Engineering, 2017.

[19] Hochschule für Technik und Wirtschaft Berlin. Wind speeds on 2017-04-18 (data). [Online]. Available: http://wetter.htwberlin.de/Download

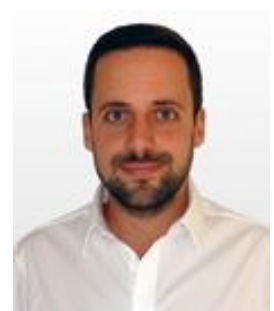

Dominik Ivo Doering was born in Salzkotten, Germany, in 1988. He received the B.Sc. degree in Environmental Engineering at the Hamburg University of Applied Sciences, Hamburg, Germany, in 2015 and the M.Sc. in Engineering, Wind Energy degree at the Technical University of Denmark, Copenhagen, Denmark, in 2017. Since then, he has been with ENERCON Service Deutschland GmbH, Aurich, Germany, where he is currently working with the grid integration of wind turbine.

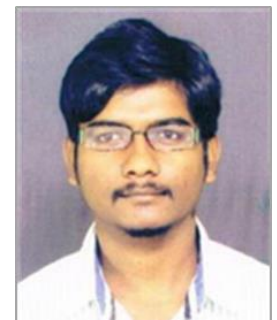

Debasish Dhua received the B.E. degree in Electrical Engineering from Indian Institute of Engineering Science and Technology, Shibpur, India, in 2015. He received the M.Sc. degree from the Department of Electrical Engineering, Technical University of Denmark, in 2017. He is currently working as a Project Engineer in PERI Lab. in Indian Institute of Technology, Kanpur, India. His research interests include the Grid-connected converter technology, Renewable Energy Integration and Microgrid.

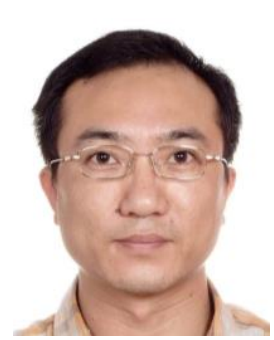

Shaojun Huang obtained the B. Eng. from Department of Electrical Engineering, Tsinghua University, Beijing, P. R. China, in 2001. He obtained the MSc from Department of Energy Technology, Aalborg University, Denmark, in 2013 and the Ph.D. degree from Department of Electrical Engineering, Technical University of Denmark, in 2017 His research interests are power system operation and control with high renewables, optimization, demand response, operation of integrated multiple energy systems and electricity markets.

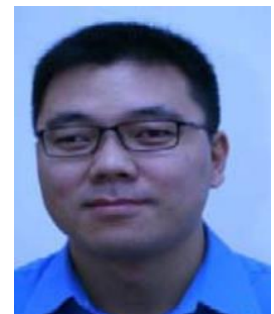

Qiuwei Wu obtained the B. Eng. and M. Eng. in Power System and Its Automation from Nanjing University of Science and Technology, Nanjing, China, in 2000 and 2003, respectively. He obtained the Ph.D. degree in Power System Engineering from Nanyang Technological University, Singapore, in 2009. His research area is power system operation and control with high renewables, including wind power modelling and control, active distribution networks, and integrated energy systems. $\mathrm{He}$ is an Editor of IEEE Transactions on Smart Grid and IEEE Power Engineering Letters. He is also an Associate Editor of International Journal of Electrical Power and Energy Systems, Journal of Modern Power Systems and Clean Energy and IET Renewable Power Generation. 